\title{
LIBERDADE E EMANCIPAÇÃO ESTÉTICA EM GIANNI VATTIMO
}

Maurício Sérgio Bergamo

\begin{abstract}
Mestre em Geografia pela Universidade Estadual do Oeste do Paraná, UNIOESTE, Brasil. Graduado em Licenciatura em Geografia pela Universidade Regional Integrada do Alto Uruguai e das Missões Campus de Erechim. Pós-Graduado (Lato Sensu) em História da Ciência pela Universidade Federal da Fronteira Sul - Campus Erechim. Pós-Graduado (Lato Sensu) em Epistemologia e Metafísica pela Universidade Federal da Fronteira Sul - Campus Erechim. PósGraduado (Stricto Sensu) em Geografia, linha de pesquisa Educação e Ensino de Geografia, da Universidade Estadual do Oeste do Paraná - Campus de Francisco Beltrão.

E-mail: mauricio_bergamob@ hotmail.com
\end{abstract}

\section{RESUMO}

Mostra algumas da principais considerações de Gianni Vattimo à noção de liberdade e emancipação estética nas sociedades da Era Pós-Moderna. Tal análise é desenvolvida pelo filósofo na Sociedade Transparente que teve a primeira publicação em 1992. Diante das sociedades pós-modernas, caracterizadas pelo profícuo desenvolvimento dos meios de comunicação em massa, Vattimo desenvolve um projeto intelectual, que tem em suas bases analíticas, a influência de importantes nomes da filosofia. Para fundamentar sua proposta filosófica, Vattimo discerne sobre o encontro das múltiplas culturas e subculturas no âmbito midiático. A proliferação de documentários e imagens que manifestam e divulgam, globalmente, na forma de meta-dados, as múltiplas cosmovisões no sistema media, possibilita o (re)conhecimento das infindas maneiras de estar no mundo. É nesse encontro dos múltiplos dialetos que há a possibilidade de liberdade e emancipação estética, se e somente se, a racionalidade e os conjuntos culturais forem desenraizados pelas dinâmicas telemáticas dos pressupostos locais. Nesse contexto, as diversas expressões de vida, as infindas imagens culturais dos inúmeros povos do planeta e a variedade de dialetos que, oscilam na rede informacional na forma de notícias, documentários ou relatos, evidencia a impossibilidade de fundamentação de um belo universal.

PALAVRAS-CHAVE: Liberdade. Emancipação Estética. (Re)conhecimento. Desenraizamento.

\section{LIBERTY AND AESTHETICAL EMANCIPATION IN GIANNI VATTIMO}




\begin{abstract}
Presents some of the main consideration made by Gianni Vattimo to the notion of liberty and the aesthetical emancipation of the postmodern Era societies. Such analysis are carried by the philosopher on the book Transparent Society, first released in 1992. Before the postmodern societies, featured by the profitable development of the mass media, Vattimo develops an intellectual project with analytical bases influenced by great names of philosophy. To justify his philosophical proposition, Vattimo discerns on the encounter of the multiple cultures and subcultures in a media context. The proliferation of documents and images that manifest and publicize, worldwide, in forms of metadata, the multiple worldviews in the media system enables the re(cognition) of the endless forms of being in the world. It is only in these encounters of the multiple dialects that the possibility of liberty and aesthetical emancipation is possible, if and only if, the rationality and these cultural collections are uprooted by the telematic dynamics of local assumptions. In this context, the different expressions of life, the endless cultural images of the countless peoples of the planet and the variety of dialects that oscillate on the informational network in form of news, documentaries or reports, demonstrate the impossibility of the foundation of a universal beautiful.
\end{abstract}

KEYWORDS: Liberty. Aesthetical Emancipation. (Re) cognition. Uprooting.

\title{
1 INTRODUÇÃ̃o
}

Gianni Vattimo é um dos filósofos mais importantes da contemporaneidade. Discípulo de Luigi Pareyson (1918-1991), Vattimo graduou-se em Filosofia na Universidade de Turim, em 1959, onde, em 1964, tornou-se professor de Estética Filosófica. Lecionando na mesma instituição em que trabalhava Hans-Georg Gadamer (1900-2002), Vattimo desenvolve uma análise da sociedade e da cultura contemporânea à luz do advento dos meios de comunicação em massa. Destacou-se na política como membro do Parlamento Europeu (1999). Atualmente, integra o Partido dos Comunistas Italianos (JAPIASSU; MARCONDES, 2006).

Reale e Antiseri (2005) destacam que Gianni Vattimo, posteriormente ao período que vai de Descartes (1596-1650) à Nietzsche (1844-1900), época marcada pelo fim da ideia unitária de progresso histórico, desenvolveu uma da mais importantes teorias estéticas do século XX. Ao passo que a modernidade secularizava a noção de história da salvação, apreendendo-a como um contínuo progresso guiado por leis de superação, vinculadas ao providencialismo e as meta-narrativas, o pensamento de Vattimo (1992) faz desaparecer as certezas fundacionais que centralizaram por muito tempo a historiografia humana, contribuindo, deste modo, ao conjunto de conhecimentos da denomina Era Pós-Moderna. A multiplicidade de diferentes centros de história, dissolveu a ideia de uma história como processo unitário e progresso 
universal e inelutável, contribuindo, em parte, com a extenuação das analíticas modernas sustentadas por valores absolutos.

As várias histórias, os diversos níveis e modos de estar na coletividade do mundo, aliadas ao desenvolvimento do sistema media, auxiliou muito a elaboração do projeto filosófico de Vattimo. É através do (re)conhecimento das pluralidades que ele desenvolve uma teoria filosófica marcada pelo encontro das várias culturas e subculturas na esfera mediática dos meios de comunicação em massa.

Para investigar a estética filosófica de Vattimo, este artigo foi estruturado em uma única seção. Deste modo, será analisado, brevemente, alguns dos principais argumentos de Vattimo a liberdade e à emancipação estética. Procura-se evidenciar, desta maneira, a importância que o sistema media e o conceito de desenraizamento assumem no projeto estético de Gianni Vattimo.

\section{DESENRAIZAMENTO E EMANCIPAÇÃO ESTÉTICA}

O projeto de Gianni Vattino na Sociedade Transparente está vinculado à Estética Filosófica. Seu objetivo é mostrar a possibilidade da emancipação estética-ontológica dos indivíduos pertencentes as sociedades Pós-Modernas. Caracterizadas por serem sociedades técnicas-informacionais, estruturadas a partir de complexos sistemas telemáticos e por mecanismos de informação e de comunicação social, nunca antes vistos até a década de setenta, Vattimo (1992) defende em seu texto, uma autêntica proposta filosófica concernente a relação entre as expressões culturais e o contexto social e histórico da Pós-Modernidade.

Influenciado, principalmente, por Friedrich Wilhelm Nietzsche (1844-1900), por Walter Benjamin (1842-1960) e por Martin Heidegger (1889-1976), Vattimo (1992) elabora seu conjunto de argumentações, levando em consideração três importantes eixos norteadores, os quais, na fundamentação de sua teoria estética-filosófica possuem intrínseca relação analítica, a saber: história, mídia de massa (mass mídia) e expressões culturais ${ }^{1}$.

O novo contexto mundial da Era Pós-Moderna, desencadeado no século XVIII com a independência dos Estados Unidos, fato que contribuiu para a descentralização do modo de vida

\footnotetext{
${ }^{1}$ Cabe destacar que essas não são as únicas influências de Vattimo (1992). Outros importantes autores também o influenciaram, tais como Karl Marx (1818-1883), Theodor Adorno (1903-1969), Jürgen Habermas (86 anos) e Karl Otto Apel (94 anos).
} 
europeu, aliado às críticas teóricas do anti-historicismo proporcionadas por Heidegger no final do século XIX, inaugurou, inéditos processos históricos, culturais e analíticos. Nesse sentido, as noções clássicas de verdade, razão, identidade, a ideia de progresso ou emancipação universal como sistema único presente nas grandes narrativas, lentamente, foi sendo substituída por uma visão de mundo contingente, diversa, instável e imprevista. A pluralidade de conjuntos culturais, nessa perspectiva, contribuiu para ocasionar mudanças significativas na noção de objetividade, de verdade, de história e, nas relações idiossincrasias entre os indivíduos ${ }^{2}$.

Houve, com o fim da Modernidade e com o início da Pós-Modernidade (final do século $\mathrm{XX}$ ), uma nova configuração global, analítica e empírica, dos aspectos históricos, sociais e culturais. De acordo com Vattimo (1992), uma das principais causas responsáveis por ocasionar essa mudança significativa de visões de mundo (Weltanschauungen), foi o advento e a intensificação dos sistemas de comunicação em massa. Essa situação é asseverado pelo filósofo em três proposições:

[...] a) que no nascimento de uma sociedade pós-moderna um papel determinante é desempenhado pelo mass media; b) que estes caracterizam esta sociedade não como uma sociedade mais «transparente», mais consciente de si, mais 'iluminada', mas como uma sociedade mais complexa, até caótica; e por fim, c) que é precisamente neste relativo 'caos' que residem as novas esperanças de emancipação (VATTIMO, 1992, p. 10).

Apesar da sociedade dos meios de comunicação ser considerada caótica, o autor afirma que, nesse contexto desorganizado, procedente dos movimentos informacionais dados pelos aparelhos midiáticos, há a possibilidade de emancipação estética dos indivíduos. Como consequência da explosão de visões de mundo (Weltanschauungen), oriundas, na Era PósModerna, da monopolização capitalista das grandes centrais distribuidoras de informações, o plano teórico do historicismo moderno, sustentando pelas meta-narrativas, sofreu severas críticas. Devido a intensificação da circulação de informações e da complexidade fenomenológica manipulada pelos sistemas midiáticos, a ideia unitária de história foi

\footnotetext{
${ }^{2}$ A vasta literatura mostra os inúmeros fenômenos históricos, sociais, econômicos, políticos, científicos e filosóficos que levaram a inauguração da Era Pós-Moderna. Não sendo objetivo de nosso artigo expor os motivos que levaram a transição ou a ruptura da Era Moderna à Era Pós-Moderna, tem-se que destacar, que estamos cientes que a construção do pensamento Pós-Moderno está, atualmente, em processo de justificação. Por isso, nesse contexto, opta-se como dois importante acontecimentos que auxiliaram à diluir a noção de curso unitário-absoluto da história e a descentralização da visão de mundo eurocêntrica na contemporaneidade, o anti-historicismo heideggeriano em âmbito analítico-filosófico e a independência dos Estados Unidos no âmbito histórico.
} 
fragmentada diante da diversidade de relatos e de micronarrativas, referentes à subculturas minoritárias ou dos povos primitivos da América e da África.

Contrariamente as perspectivas da filosofia da história modernas, em que a busca pela razão humana em termos absolutos foi o princípio de fundamentação da ideia de história universal e do caráter emancipador dos indivíduos, Vattimo (1992) destaca que, nas sociedades da Era Pós-Moderna, onde predomina a mass media, é impossível apreender o curso da história em termos universais ou unitários e, inverossímil conceber o sujeito humano, através de processos racionalistas, como independente ou emancipado.

Nesse sentido,

A tese que pretendo propor é que na sociedade dos media, em vez de uma ideal de emancipação modelo pela autoconsciência completamente definida, conforme o perfeito conhecimento de quem sabe como estão as coisas (seja ele o espírito Absoluto de Hegel ou o homem não mais escravo da ideologia como o pensa Marx), abre caminho a um ideal de emancipação que tem antes na sua base a oscilação, a pluralidade, e por fim o desgasta do próprio 'princípio da realidade' (VATTIMO, 1992, p. 13).

A divulgação de modos de vida distintos dos ideias europeus através dos sistemas de informações em massa, possibilitou oportunidades para que os relatos históricos das minorias étnicas ou de grupos sociais minoritários viessem à tona e, pudessem ser re(conhecidos) por outros conjuntos sociais.

Assim, "O ideal europeu de humanidade revelou-se como um ideal entre outros, não necessariamente pior, mas que não pode, sem violência, pretender valer como verdadeira essência do homem, de qualquer homem” (VATTIMO, 1992, p. 10).

Levando em consideração tal circunstância, no mesmo instante em que a lógica perversa do capitalismo manifesta os diferentes dialetos, as múltiplas vivências humanas, como imagens transfiguradas em mercadorias informacionais, a realidade empírica, de acordo com o autor, é modelada, arranjada ou arquitetada, pela pluralidade de pontos de vista e pelos modos variados de conceber os fenômenos mundanos.

Nesse aspecto, Vattimo (1992, p. 13) expõe:

De fato, a intensificação das possibilidades de informação sobre a realidade nos seus mais variados aspectos torna cada vez menos concebível a própria ideia de uma realidade [...]. Realidade, para nós, é mais o resultado do cruzamento, da 'contaminação' (no sentido latino) das múltiplas imagens, interpretações, reconstruções que, em concorrência entre si ou, seja como for, sem qualquer coordenação central, os media distribuem. 
A pluralidade das culturas e o encontro com outras cosmovisões e formas de vida, emergentes da mass media, para o autor, são os principais fatores positivos das sociedades pósmodernas. O encontro entre a multiplicidade de dialetos e o conjunto telemático dos serviços informacionais, se por um lado ocasionou a ruptura da ideia de história unitária, por outro, possibilitou, globalmente, a verificação de contextos sociais específicos. A particularidade dos signos culturais, devido a oscilação de imagens, informes e notícias que circulam no meio informacionais, explicita o caráter pluralístico da realidade e possibilita a emancipação do indivíduo pela tolerância e pelo (re)conhecimento das diversas culturas das sociedades.

O (re)conhecimento das diversidades culturais, é apresentada por Vattimo (1992) como o instante em que os infindos dialetos do mundo se encontram no sistema media. Para o filósofo, a confluência entre os diferentes grupos culturais no sistema media possibilita a assimilação de seus costumes, hábitos e comportamentos, por outros grupos socioculturais.

Assim,

A libertação das diversidades é um ato com que elas 'tomam a palavra', se apresentem, se 'põe em forma' de modo a poderem tornar-se reconhecidas [...]. O efeito emancipador da libertação das racionalidades locais não é todavia apenas o de garantir a cada uma delas um mais completo reconhecimento e 'autenticidade' [...]. O sentido emancipador da libertação das diferenças e dos 'dialetos' consiste mais no efeito global de desenraizamento que acompanha o primeiro efeito de identificação. Se falo o meu dialeto, finalmente, num mundo de dialetos entre outros, se professo o meu sistema de valores - religiosos, estéticos, políticos, étnicos - neste mundo de culturas plurais, terei também uma consciência intensa da historicidade, contingência, limitação, de todos estes sistemas, a começar pelo meu (VATTIMO, 1992, p. 15).

A possibilidade de emancipação, dada pelo encontro das minorias sociais e culturais no âmbito da mass media, condiz com o que o autor denota por desenraizamento. Este termo se refere à libertação das diferenças, dos elementos locais, dos dialetos. As vivências, ao se encontrarem com os sistemas de informação de massa, possibilita o (re)conhecimento da multiplicidade das racionalidades locais e a constatação da grande variedade de micronarrativas históricas. Nesse sentido, tem-se um desenho poli nucleado das mais variadas histórias e dos mais variados modos de vida. (Re)conhece-los e tolerá-los como tais, possibilita a emancipação dos sujeitos humanos.

Entretanto, essa ideia de emancipação corresponde a: 
[...] uma liberdade problemática, não só porque este efeito dos media não é garantido, é apenas uma possibilidade a reconhecer e a cultivar (os media podem também ser, sempre, a voz do 'Grande Irmão'; ou da banalidade estereotipada, do vazio de significado); mas também porque nós mesmos não sabemos muito bem que aspecto tem - custa-nos a conceber esta oscilação como liberdade: a nostalgia dos horizontes fechados, ameaçadores e tranquilizadores ao mesmo tempo, continua ainda radica em nós, como indivíduos e como sociedade (VATTIMO, 1992, p. 16-15)³.

Consoantemente, em contraposição ao desenraizamento, ligado ao pronunciamento das micronarrativas locais no sistema de media, a possibilidade de abertura ao mundo das subculturas minoritárias e a emancipação, há, de acordo com o autor, o sentimento de pertença. Todavia, no entendimento de Vattimo (1992), a pertença não está vinculada a multiplicidade e a pluralidade social, cultural e historial. Por não estar ligada aos media, o sentimento de pertenca encerra os dialetos e as singulares visões de mundo (Weltanschauungen) em horizontes fechados, ameaçadores e melancólicos.

Nesse sentido, faz-se necessário desmistificar, desenraizar, por meio dos aparelhos técnicos da mass media, os inumeráveis dialetos culturais existentes no mundo. A interiorização dos fenômenos mundanos através da circulação dos meta-dados informacionais (como imagens, figuras e efígies), favorecem o contingente (re)conhecimento e tolerância das múltiplas vivacidades históricas, sociais e estéticas.

Nessa perspectiva, os meta-dados informacionais são todos aqueles informes, todos aqueles comunicados, todos os anúncios com ilustrações figurativas ou diálogos vocacionais em caráter digital, que ao exporem os dialetos locais no sistema media, possibilita o (re)conhecimento de determinada subcultura.

Essa situação é exposta pelo autor da seguinte maneira:

[...] há uma espécie de entropia ligada à própria multiplicação dos centros da história, isto é, dos lugares de recolha, unificação e transmissão das informações. A ideia de uma história mundial, nessa perspectiva, revela-se aquilo que de fato sempre foi: a redução do curso de acontecimentos humanos sob uma perspectiva unitária que é também sempre função de um domínio, seja ele domínio de classe, domínio colonial, etc (VATTIMO, 1992, p. 29).

\footnotetext{
${ }^{3}$ A O Grande Irmão faz referência ao personagem fictício, do romance, 1984, de George Orwell. O Grande Irmão, nesse sentido, é utilizado pelo autor para indicar a manipulação dos desejos pessoais através dos aparelhos midiáticos. Vattimo (1992) reconhece tal problemática. Todavia, a constatação de Vattimo, das intencionalidades capitalistas nos media, leva-o a desenvolver uma teoria, em que o embate acionário contra as classes hegemônicas, assim como propôs Benjamin, não se faz presente. $\mathrm{O}$ (re)conhecimento e a tolerância das diversas culturas e das diferentes visões de mundo (Weltanschauungen), por meio dos sistemas da media, já oportuniza a emancipação.
} 
$\mathrm{Na}$ medida em que as experiências históricas, sociais e estéticas emergem e são difundidas no sistema das media, permitindo assim que, os dialetos se transformem em dados informacionais para movimentarem-se no âmbito global, para haver a possibilidade de serem re(conhecidos), a representação societária poli nucleada torna-se evidente. Veja-se:

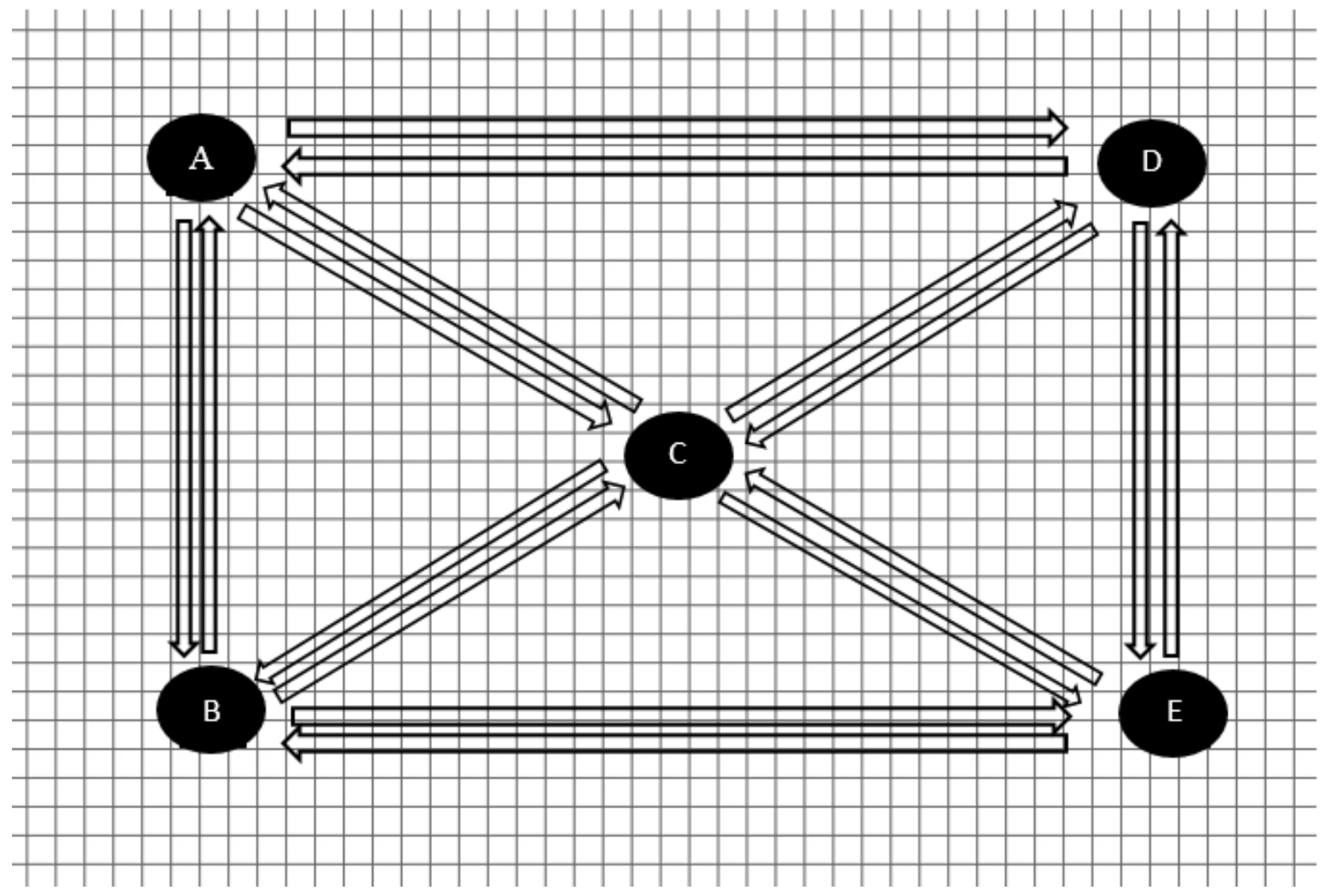

Figura 1 - O sistema media e a multiplicação de centros de história.

Fonte: Elaborado pelo autor, 2016.

Em conformidade com a Figura 1, a malha quadriculada ao fundo representa as sociedades pós-modernas, caracterizadas, de acordo com Vattimo (1992), por suas complexas redes de telecomunicação, os media. Sobre a malha quadriculada, os sinais gráficos $(A, B, C$, $D, E$ ) indicam os múltiplos centros culturais. As setas mostram a interlocução e o movimento informacional entre os vários dialetos existentes nas sociedades da Era pós-moderna.

Nessa perspectiva, percebe-se que os sistemas telemáticos possibilitam o encontro e o (re)conhecimento das várias visões de mundo (Weltanschauungen), dos múltiplos centros culturais das sociedades pós-modernas. A oscilação dos meta-dados informacionais, destacadas pelas setas (de ida e de volta), equivalem ao desenraizamento das racionalidades locais. É no (re)conhecimento dos dialetos de $(A$ e $C),(A$ e $D)$ ou $(E$ e $B)$ ou de qualquer outra relação 
estabelecida entre os centros culturais através dos medias, que, há a possibilidade de emancipação estética dos indivíduos ou das subculturas.

Entretanto, necessariamente, $C$ não indica o centro unitário - histórico da malha. A malha poderia ser infinitamente duplicada e outros múltiplos centros culturais poderiam aparecer nesse desenho poli nucleado. Com efeito, todos os centros culturais com suas visões de mundo e dialetos seriam, possivelmente, re(conhecidos) por seus diferentes modos de vida. É nesse (re)conhecimento e nessa tolerância que reside, segundo Vattimo (1992), a emancipação estética dos indivíduos ou das subculturas.

Nesse interim o autor defende que:

A cultura de massa não nivelou de forma alguma a experiência estética homologando todo o 'belo' aos valores daquela comunidade - a sociedade burguesa europeia - que se sentia portadora privilegiada do humano; pelo contrário, evidenciou de modo explosivo a multiplicidade dos 'belos' dando a palavra a culturas diversas [...] mas também a «subsistemas» internos a própria cultural ocidental (VATTIMO, 1992, p. 72).

Devido à explosão de subsistemas culturais e a impossibilidade de conceber a história como um curso unitário, a experiência estética dissolveu-se e passou a ser concebida de maneira distinta das tendências filosóficas modernas. A expressividade cultural constatada pelos sistemas de comunicação em massa que revelaram a pluralidade estética dos mais diversos grupos e subgrupos sociais, impossibilitou a concepção universal do belo. A experiência do belo, passou a estar vinculada, fundamentalmente, às experiências particulares de cada comunidade que, para emancipar os indivíduos, necessariamente, devem ser desenraizadas dos ditames locais através da oscilação midiática.

Nesse contexto, a essência da experiência estética do belo (Wesen), conforme destaca Vattimo (1992), passou a corresponder à liberação das emoções artísticas na esfera dos sistemas de comunicação em massa. Embora o autor reconheça a manipulação do belo nas sociedades da técnica e da persuasão total ( $G e$-Stell), ele afirma que, em meio ao caos promovido pelas sociedades capitalistas-industriais da Era pós-moderna, a exposição das obras de arte nos sistemas media oportuniza a representação verdadeira do ser por meio da interpretação hermenêutica fenomenológica ${ }^{4}$.

\footnotetext{
${ }^{4}$ Nesse momento não cabe desenvolver as hermenêuticas filosóficas de Heidegger e de Gadamer. Tal tarefa demandaria longas discussões analíticas que poderiam fazer perder o foco de nossa investigação. Entretanto, são essas duas vertentes que concernem ao projeto intelectual de Vattimo a possibilidade de fundamentação de uma
} 
Essa situação é apresentada da seguinte maneira:

Isto é, continua a parecer que se trata de «salvar» uma essência da arte (criatividade, originalidade, fruição da forma, conciliação, etc.) das ameaças que as novas condições de existência da civilização de massa representam não só para a arte, digamos, mas para a própria essência do homem. As condições de reprodutibilidade, em particular, são consideradas inconciliáveis com as exigências da criatividade que parece indispensável na arte, não só porque a rápida difusão das comunicações tende a banalizar imediatamente qualquer mensagem [...] mas sobretudo, porque se reage a este consumo dos símbolos, através da invenção de 'novidades' que, como as da moda, não possuem radicalidade que parece necessária à obra de arte, antes se apresentando como jogos superficiais (VATTIMO, 1992, p. 63).

As sociedades industriais tendem a transformar os objetos de arte em utensílios rapidamente consumíveis. O Wesen da experiência estética, nas sociedades tardomodernas, de acordo com Vattimo (1992), adaptam-se às exigências capitalistas do mercado e da moda. Porém, para que o valor de troca não se sobreponha ao valor cultural da representação artística, para que não haja a restrição do Wesen na experiência estética, é preciso, necessariamente, apreender a dramatização vívida da obra de arte. É essa interpretação enfática da representação artística, ligada aos dialetos e as visões de mundo, elucidadas nas obras de arte através dos sistemas da media, que possibilita o (re)conhecimento das subculturas, a liberdade, e a emancipação estética, se e somente se, forem desenraizadas dos pressupostos locais.

Assim,

A experiência estética tornar-se inautêntica quando, nas condições atuais de pluralismo vertiginoso dos modelos, o reconhecimento que um grupo realiza de si mesmo nos próprio modelos se vive e se apresenta ainda na forma de identificação da comunidade com a própria humanidade; isto é, apresenta o belo, e uma determinada comunidade que reconhece, como um valor absoluto. A 'verdade' possível da experiência estética da modernidade avançada é provavelmente o 'coleccionismo', a mobilidade das modas, o museu também; e afinal, o próprio mercado, como lugar de circulação de objetos que desmistificaram a referência ao valor de uso e são puros valores de troca: não necessariamente apenas de troca monetária, mas de troca simbólica (VATTIMO, 1992, p. 75).

hermenêutica fenomenológica. Cabe destacar, brevemente, que a exposição das obras de arte no sistema media, para Vattimo (1992), possibilita uma interpretação em caráter fenomenológico. Em termos heideggerianos, a interpretação fenomenológica das obras de arte no sistema de media, ligada a apreensão dos sentimentos motores que constituem as representações artísticas, equivaleria, a verdade do ser jogado na clareira. Para o leitor que desejar maiores informações sobre a 'clareira do ser', faz-se necessário consultar a Carta Sobre Humanismo de Martin Heidegger. Tal texto está disponível na Coleção Os Pensadores de 1973. 
Em conformidade com o autor, nas sociedades da Era pós-moderna é impossível o belo em caráter universal. As diversas expressões de vida, as infindas imagens culturais dos inúmeros povos do planeta e a variedade de dialetos que, oscilam na rede informacional na forma de notícias, documentários ou relatos, evidencia a impossibilidade de fundamentação de um belo universal. É a troca simbólica realizada entre a pluralidade de semblantes culturais, ligados aos mais diversos grupos sociais residentes no mundo real, que determina a heterotopia do belo. Essa heterotopia do belo, conforme afirma o autor, apesar de ser emergente dos sistemas de mídia, está vinculada ao sentido ontológico do ser no mundo.

Com isso,

O belo não é o lugar de manifestação de uma verdade que nela encontra a expressão sensível, provisória, antecipadora, educativa, como muitas vezes pretendeu a estética metafísica da tradição. A beleza é o ornamento no sentido em que o seu significado existencial, o interesse a que responde, é a dilatação do mundo da vida num processo de chamadas a outros possíveis mundo de vida, que não são, porém, apenas imaginários ou marginais ou complementares ao mundo real; mas compõe, constituem, no seu jogo recíproco e com seu resíduo, o chamado mundo real. A essência ornamental da cultura da sociedade de massa, o caráter efêmero dos seus produtos, o ecletismo que a domina, a impossibilidade de reconhecer neles uma qualquer essencialidade [...] corresponde plenamente ao Wesen do estético na modernidade avançada (VATTIMO, 1992, p. 76-77).

A proliferação de belezas confere ao belo seu caráter heterotópico. A essência da experiência estética do belo (Wesen), assim, é apreendido na constatação da multiplicidade de vivencias culturais que o sistema midiático promoveu. Da mesma maneira que não há um curso unitário da história, não há apenas um único núcleo de experiência estética. A disseminação de perspectivas culturais promovida pela telemática, vinculou a essência da experiência estética, ao (re)conhecimento e a tolerância dos múltiplos modos de estar no mundo, seja de indivíduos ou de comunidades.

A essência da experiência estética do belo, na perspectiva de Vattimo (1992), fundamenta-se no encontro das inúmeras culturas existentes no planeta, através dos sistemas de telecomunicação em massa. Por mais distantes que estejam umas das outras na superfície terrestre, o sistema media, possibilita o encontro e o (re)conhecimento dos hábitos e dos costumes de cada grupo cultural. A transição das informações em forma de imagens digitais, propagandas comerciais ou anúncios ligados ao enraizamento de cada grupo, povo ou nação, possibilita a constatação dos infindos dialetos e das inúmeras visões de mundo 
(Weltanschauungen) efetivadas na Terra. Nesse movimento proporcionado pela estrutura física-tecnológica que auxilia a propagação desses meta-dados informacionais, ou seja, pelo sistema media, há a possibilidade do encontro, do (re)conhecimento e da tolerância dos imensuráveis dialetos do nosso planeta. Nisso reside, segundo Vattimo (1992), o Wesen, a essência da experiência estética do belo.

Encaminhando as discussões para as considerações finais, é preciso destacar que, a essência da experiência estética em Vattimo (1992), apresenta-se pelo o (re)conhecimento e pela tolerância da pluralidade de culturas e subculturas que oscilam na forma de meta-dados informacionais nas redes de comunicação em massa. Na medida em que as visões de mundo são desenraizadas das racionalidades locais para oscilar na esfera mediática, há o (re)conhecimento e consequentemente a emancipação estética dos indivíduos ou dos grupos sociais. Assim, a pluralidade e a tolerância dos muitos modos de estar no mundo, torna-se o cerne da filosofia estética de Gianni Vattimo.

\section{CONSIDERAÇÕES FINAIS}

O percurso que apreendeu-se até aqui, objetivava, em um primeiro momento, identificar os principais aspectos das sociedades da Era Pós-Moderna. Em Vattimo (1992), constatou-se que, o principal pressuposto das sociedades pós-modernas é o advento do sistema media, dado de maneira mais intensiva, a partir da década de setenta. Paralelamente, analisou-se alguns dos principais argumentos do filósofo às dinâmicas históricas e sociais promovidas pelo sistema midiático. Investigando esses aspectos, conseguimos obter as ferramentas necessárias para avançarmos e compreendemos, suscintamente, a relação entre a sociedade pós-moderna da comunicação em massa e a noção de liberdade e emancipação estética, seja dos indivíduos ou dos vários grupos sociais pertencentes as sociedades. Assim, tivemos a oportunidade de acompanhar, brevemente, a maneira pela qual Gianni Vattimo propõe sua filosofia estética, partindo de uma análise histórica e social da contemporaneidade. Nesse sentido, as prerrogativas do autor levam aos seguintes esclarecimentos:

a) O contexto mundial da Era Pós-Moderna, emergente da descentralização do ideal de vida europeu, instaurou processos históricos e sociais extraordinários, se comparados ao contexto global da modernidade. Como consequência da explosão das novas visões de mundo (Weltanschauungen), evidenciadas pelos relatos de civilizações até então desconhecidas e, pela 
intensa oscilação de informações no âmbito midiático, dissolveu-se a ideia de progresso unitário da história. O canal dos media, assim, oportunizou o encontro das diversas culturas e subculturas, rescindindo, desta maneira, com a noção unitário de um curso histórico e social.

Na caótica sociedade dos meios de comunicação em massa, controlada pelas dinâmicas perversas do modo de produção capitalista, que tende a transformar todos os acontecimentos culturais em valores quantitativos concernentes a óptica mercantilista, há, a possibilidade de liberdade e emancipação estética. Com o advento dos sistemas de informação, os dialetos culturais de grupos sociais minoritários puderam ser (re)conhecidos. O encontro dos diversos semblantes estéticos na esfera informacional, desta maneira, possibilitou a legitimação de cosmovisões e formas de vida distintas dos modelos eurocêntricos. Tal situação depreende um segundo esclarecimento:

b) $\mathrm{O}$ pressuposto fundamental da liberdade e da emancipação estética é o desenraizamento. Na medida em que os dialetos oscilam na esfera informacional na forma de meta-dados, há a possibilidade das racionalidades locais serem re(conhecidas). Assim, as inúmeras expressões culturais existentes no mundo real, ao se movimentarem nos media modelam um desenho poli nucleado, devido a multiplicidade de centros históricos, sociais e estéticos. Essa situação, ao invés de tornar significativas as meta-narrativas (como pretendia as vertentes da Filosofia Moderna), oferece ênfase às micro-narrativas locais. Estas, no entanto, se tornam relevantes, se e somente se, se desenraizarem dos aspectos conterrâneos para oscilar globalmente no domínio informacional. Fato que possibilita o (re)conhecimento. Desta conclusão, infere-se outra:

c) $\mathrm{Na}$ oscilação dos meta-dados informacionais, para não perder-se a essência da experiência estética do belo (Wesen), faz-se necessário apreender o horizonte vívido das expressões culturais que circulam no meio informacional. Estando ligadas ao infindos grupos sociais existente no mundo, logo, há uma imensa pluralidade de experiências estéticas. O (re)conhecimento e tolerâncias destas, nas sociedades tardomodernas, tornar-se a essência da experiência estética do belo.

Finalizando este artigo, ressalta-se que tentou-se demonstrar, através da leitura do texto de um dos principais personagens de todos os tempos, o projeto intelectual de Gianni Vattimo. Os conceitos que foram desenvolvidos neste artigo, mesmo de modo específico e sucinto, abrem caminho para estudantes e profissionais pesquisarem a filosofia estética de Gianni Vattimo. 
Com isso, a escolha do tema deste artigo, preocupou-se em desenvolver, dentro do possível, os conceitos específicos de media e desenraizamento, evidenciando, sua articulação a noção de liberdade e emancipação estética. Nesse sentido, acredita-se que o esforço desempenhado na elaboração deste artigo, outorgue os objetivos incialmente expostos.

\section{REFERÊNCIAS}

JAPIASSU, Hilton; MARCONDES, Danilo. Tradução de Ivo Storniolo. São Paulo, SP: Paulus, Dicionário Básico de Filosofia. Rio de Janeiro, 2005. (Coleção História da Filosofia, 6).

RJ: Jorge Zahhar, 2006.

REALE, Giovanni; ANTISIERI, Daria. História

VATTIMO, Gianni. A Sociedade Transparente. da Filosofia. De Nietzsche à Escola de Frankfurt. Lisboa, Portugal: Antropos, 1992.

BERGAMO, Maurício Sérgio. Liberdade e Emancipação Estética em Gianni Vattimo.

Complexitas - Rev. Fil. Tem., Belém, v. 1, n. 2, p. 10-23, jul./dez. 2016. Disponível em:< http://www.periodicos.ufpa.br/index.php/complexitas/article/view/3797>. Acesso em: 20 abr. 2017. 